\title{
The Adhocracy Structure and its impact on Strategic Performance - A field study of a number of private industrial companies in Kirkuk Governorate
}

\author{
Modaffer Ahmed Hussein \\ \{Email: mudafer1975@yahoo.com\}
}

North Technical University / Technical Institute - Hawija, Iraq.

\begin{abstract}
In order for the organizations to be competitive, they must pay attention to the adhocracy structures where the organization will be able to enhance its strategic performance and work effectively in an uncertainty environment. The research problem came through questions about whether there are a correlation, effect and contribution to the adhocracy structures of the strategic performance. The importance of the research comes from the role of the adhocracy structure in contributing to supporting strategic performance. The research aimed to provide a theoretical framework and analysis of the relationship of linkage and impact and the extent of the contribution of the adhocracy structure to strategic performance. Hypotheses were formulated and tested using the opinions of the individuals in the sample. The research reached several conclusions confirming its hypotheses, and the objective structure identified $64 \%$ of the change in strategic performance. The research concluded with a set of conclusions and recommendations.
\end{abstract}

Keywords: Adhocracy Structure, Operating Adhocracy, Administrative Adhocracy, Strategic Performance

\section{Introduction}

The interest in organizations with flexible structures has increased due to the impact of the need for organizations to be more competitive and sustainable, as the organization will be able, through the adhocracy structure, to maintain its competitive advantages. If organizations want to be effective and remain in an environment of uncertainty, they must rely on structures Flexibility. The emergence of concepts of strategic performance and attention to the competitive nature of the domestic market, which has become a marketer for foreign products, which constitute a major challenge and influencing national organizations that are weak in their management, efficiency and difficulty in adapting to international competition, and even local as well, so this is imperative organizations from being flexible organizations to face challenges in order to survive and grow to enhance their performance and strategic capabilities.

This research was dealt with through three axes, the first axis dealt with the theoretical framework for the adhocracy structure and strategic performance, while the second axis dealt with the research methodology, while the third axis dealt with the analysis of the results and the test of hypotheses, and concluded the research with the conclusions reached and some recommendations.

\section{Theoretical Framework}

\subsection{Concept of the Adhocracy Structure}

When an organization faces a dynamic and complex environment, its structure must be flexible and adaptable. Knowledge and skill are a requirement to accomplish tasks, and the scope of problem-solving extends to many areas, so information is very valuable and its continuous flow is necessary to ensure ideal solutions [1]. The organizational structure is the framework that determines all the interactions that take place between individuals. Organizations are working to develop modern structural options that can help companies compete efficiently and effectively [2]. The adhocracy structure is characterized by high horizontal differentiation, little vertical differentiation, low formalization, and great flexibility in response [3]. Horizontal differentiation is high in the objective organization due to the predominance of the number of professionals with rare experiences, while vertical differentiation is low because the 
multiplicity of administrative levels would hinder the organization's ability to adapt [4]. And the need for supervision is at its lowest level because these professionals are highly capable and experienced in finding or applying desired behavior by management [3].

Individuals in adhocracy organizations such as design or laboratory research companies tend to be more general, and this reflects the low structural complexity, and they are given wide discretion to perform their duties, and the decision-making process is delegated to the lower administrative levels of the organizational hierarchy [5]. Because this structure is very flexible, large parts of the organization are organized in the form of temporary project teams that solve the problems that those projects face individually. And that these groups of groups operate the mechanism of mutual adaptation as a preferred coordination mechanism, and often everyone can participate on the basis of units. The internal coordination of groups and contacts with the strategic summit is done through communication techniques and channels [1].

Adhocracy organization is self-renewing, it is an organic structure, and we can liken it to a tent instead of a palace. The tent can be quickly assembled and moved at any time. The same applies to the object, as it changes from its internal form continuously and quickly as well. The solution to problems in the adhocracy is an original or an uncommon solution since the creative organization cannot rely on any form of standardization to coordinate the work [3]. The adhocracy structure seeks to maximize satisfaction, flexibility and continuous development [6]. And that the administration is doing everything it can to ensure everything that nurtures creativity. Where individuals work outside their units, which gives rise to unconventional ideas [1].

\subsection{Parts of the adhocracy}

There are two main parts to the adhocracy: the operating adhocracy and the administrative adhocracy, as follows: [7].

\subsubsection{The Operating Adhocracy}

The Operating Adhocracy is that you create and solve problems directly on behalf of clients. To achieve this it has specialized teams that work mostly under contracts. As is the case with a creative organization. In each operating adhocracy, there is an administrative adhocracy parallel to it. Because the operating adhocracy is for customers, we find it busy in innovative efforts to discover authentic solutions to the problems presented to it by customers. In order to achieve this, the specialists must interact indirectly through a mechanism of mutual adaptation, as a mechanism for coordinating organically structured project teams [3] It is distinguished through the largest and most important operational center, and problems are solved on the basis of clients, and the administrative and operational work is usually mixed together in a unified effort. As the operating adhocracy attempts to reach a creative and unique solution to each new problem [1]. The main characteristic of the operating adhocracy is that its administrative and operational work is combined in one effort. Here, we cannot separate the planning and operational efforts, both of which need the same specialized skills within the framework of a single project [7].

\subsubsection{The Administrative Adhocracy}

The administrative adhocracy is the second major part that works with project teams but in a different direction. At a time when the operating adhocracy is directed towards customer service, the administrative adhocracy is directed to service itself [3]. Differently from the operating adhocracy, and this makes a border between the operational center and the administration because the operational center is usually organized in the form of separate units and is accessed through specific criteria from the outputs [1]. Where the operational center is reduced for the administrative component to remain as adhocracy structure. This reduction, reduction, or separation and determination of the operational center can be accomplished in several ways, including separating production operations in an independent organization that owns a department with a connection to the strategic summit of the parent organization, thus ridding the administration of problems and creating an administrative component in the organization to structure organically for the purpose of creativity. Also, the operational center can operate with complete independence, and this allows senior management to contract with other organizations to accomplish it. Also, the shortcut is easy when it is It is possible to manage productive operations automatically, and this leads to abbreviation because the automation of the operational center facilitates self-management and this frees it from direct supervision or any of the control methods exercised by the administrative 
component. It allows senior management to pay attention to designing tomorrow's business, not today's business [7].

Through the adhocracy structure, the administration will flatten the hierarchy and reduce the totals. Vertical teams, which include the CEO and middle management managers, supervisors and employees, will exercise decision-making and use a 360-degree method of performance appraisal, according to which all of these process the process of evaluating the performance of each individual in the organization. Management can cut horizontal relationships by transferring information between individuals [2]. And when the organization wants to be able to adapt and be creative, then the organization needs to cooperate with several specializations to achieve a general goal, and when the tasks are technical and not programmed and it is difficult to accomplish by one person, then the adhocracy becomes the appropriate organizational design [7].

After what was presented, we believe that the adhocracy structure is the structure that is characterized by high horizontal differentiation and little vertical differentiation, low official and great flexibility. And that the target environment is dynamic, because creative works need high levels of flexibility, and this is what the organization's adhocracy structure provides.

\subsection{Concept of Strategic Performance}

Strategic performance is the mirror that reflects the success or failure of organizations, and performance has been defined as a reflection of how the organization uses its material and human resources and exploits them in a way that makes them able to achieve the goals they set [8]. Performance refers to those results obtained from operations, and that performance allows us to conduct a comparison process with other organizations. The strategic performance, in general, revolves around the ability of the organization to reduce the costs of its activities or the estimated value of buyers compared to competitors or when the demand to buy the organization's products is better Among the competing alternatives [9]. Strategic performance defines as the organization's ability to achieve goals and objectives [10]. And defines strategic performance as translating strategic plans into results and assisting managers to respond quickly and effectively to unexpected changes. We can also look at strategic performance as knowing how the organization works in aggregate [11].

After this presentation of definitions that dealt with the concept of strategic performance, we believe that the strategic performance can be seen as being the nature of the action required by the organization to achieve Its objectives, which is also the path that the organization is taking at the lowest possible costs and the best competitive force achieved by this performance.

The difference in the goals of the organizations made the process of measuring strategic performance different from one organization to another with different goals. To measure the organization's strategic performance, it can focus on measuring financial goals alone, measuring social goals, or using financial and social indicators together, and the more diverse the goals" the more difficult it is to measure. And since each organization has its own and related strategy With its long-term vision, and that the assessment and measurement of performance depend on this strategy, and that the strategic performance measure must be directed to the future, and that the current capacity must define its strategy in the beginning, and then develop the measurement and evaluation system that should be used according to this basis strategy [12].

\subsection{Measurement approaches of Strategic Performance}

\subsubsection{Financial Approach}

The organization uses, according to this approach, many financial indicators to measure strategic performance, as it shows the financial position of organizations, which can be prepared within predictive models to determine the financial position of organizations during future periods [13]. And that the most important financial indicators that are used to measure strategic performance are the return on investment, the return on the right of ownership, the return on the shareholders and the market share. The financial indicators are important indicators of strategic performance for two reasons. The first is that the market represents an important part of the business environment and is the main source of opportunities and threats in the stage of formulating the strategy. It is related to the market share rate, which is linked to critical strategic factors, such as market valuation, number of competitors, and market division [14].

\subsubsection{Cognitive Approach}


The customer perspective is the one that determines and decides the strategic success of the organization according to this approach, as the customer alone is able to define the success of the specific mix of the product and many indicators describe customer perceptions and aspirations. Therefore, one indicator describes the complex competitive advantage based on different activities. It is rare to use it, therefore there is a need for several indicators to achieve this, which is a mixture of quantitative and qualitative indicators that are greatly affected by cognitive sciences. Therefore, the in-depth interviews with customers and represented by the stories told by customers positively and negatively, but represent the largest part of this approach, and gives the Customers during these interviews have the opportunity to express their experiences, practices and aspirations according to their vision [15].

\subsubsection{Stakeholders' Approach}

There are two groups of stakeholders, the first is the environmental group, which includes customers, owners, and society, and the second is the group of operations, which includes workers and suppliers, and that the contribution of stakeholders in achieving the main goals of the organization is through visible and hidden contracts between them and the organization, and the organization works to assess the extent of Their plans are in line with the expectations and aspirations of the stakeholders. These contracts are called secondary goals, which support the main and primary goals of the organization. This approach is based on the fact that performance measurement systems based on traditional accounting methods are not suitable for the current organizations in which relationships with workers, customers, suppliers, and owners have changed, so it is necessary to develop measures capable of understanding intangible factors such as services and innovations where The participant's entrance, i.e. performance measurement using the participant's method, is considered able to "capture strategic planning issues while directing the organization's options for strategic planning for the design of a performance measurement system [16].

\subsubsection{Competitive Values Approach}

According to this approach, strategic performance is classified according to two indicators. The first is the level of focus if it is internal, that is, the external relationship, that is, the organization's relationship with its environment. The second is the organizational structure and whether it is an "organic" structure. Combining the two indicators together will lead to the emergence of four models. The first is the system model, which focuses on flexibility, adaptation, and competitive position and arises when the structure is organic and the focus is external. The second is the planning model and focuses on productivity, efficiency and profitability and arises when the structure is automatic and the focus is external and the third is the innovation and development model and focuses on creating opportunities and employee satisfaction and employee development and arises when the structure is organic and focus is internal the fourth is the internal operations model and focuses on indicators for maintaining the balance of internal processes and the current competitive position and arises when the structure is automated and the focus is internal. These four models represent conflicting values as the organization determines the appropriate input to its capacity and attitude variables, where the modern organization focuses on creativity and flexibility in acquiring resources and is less interested in indicators of efficiency and productivity, while more mature organizations focus on adopting planning and operations models to ensure profitability and balance in the business environment [10].

\section{Methodology}

\subsection{The research problem}

The Adhocracy Structure in the twenty-first-century organization has become a necessity to stay in an era in which flexibility has become a basis for competition, and that the fact that an organization possesses an Adhocracy Structure will determine its ability to survive and compete and thus achieve Strategic Performance, which is what the organization seeks. Here we can formulate the research problem in the form of the following question: Does the fact that an organization operates according to the adhocracy structure will contribute to enhancing its strategic performance and how does this affect strategic performance.

\subsection{The importance of research}


The research derives its importance from the role that the organization's purpose structure plays in achieving great accomplishments, which positively contributes to supporting its strategic performance, as the flexible organization provides the ability to compete by having an important element in the field of competition, which is flexibility and adaptation to achieve excellence in performance.

\subsection{Research objectives}

The research seeks to provide a theoretical framework for the purpose structure, its main dimensions and strategic performance, in addition to achieving the following basic goals are: Analyze the correlation and impact relationship between the objective structure and its dimensions and strategic performance. Explain the extent to which the purpose structure contributes to strategic performance. Reaching results in light of the analysis data to determine the proof or rejection of the research hypotheses.

\subsection{Research model}

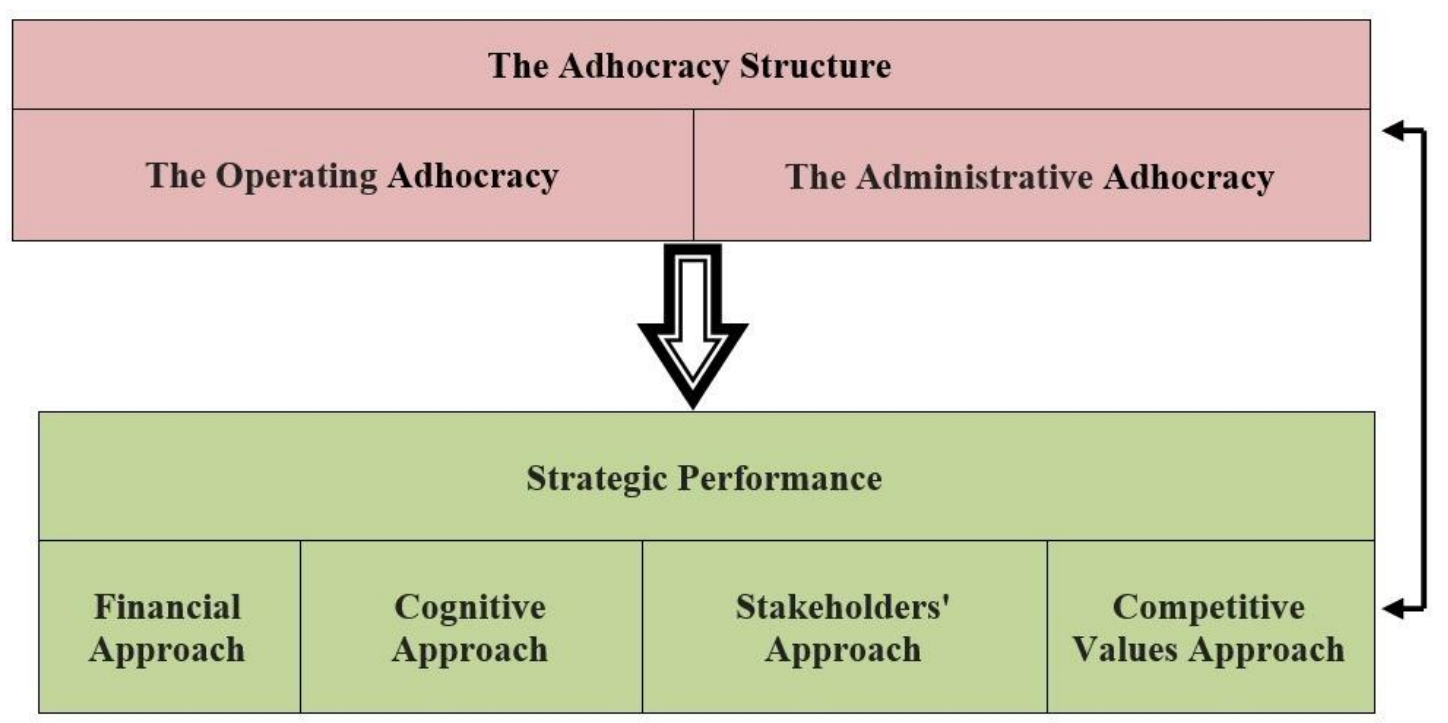

Fig .1. Research model

\subsection{Research hypotheses}

The research assumed three hypotheses as follows:

First hypothesis: There is a positive correlation between the Adhocracy Structure with its Strategic Performance of the researched organizations.

Second hypothesis: There is a significant effect of the Adhocracy Structure of the Strategic Performance of the researched organizations.

Third hypothesis: The Adhocracy Structure contributes to the Strategic Performance of the researched organizations.

\subsection{Research method}

The research relied on exploratory, descriptive and analytical methods. The data were collected by seeking a sample opinion from company managers and heads of departments therein, and then these answers were described and finally analyzed to test the hypotheses. 


\subsection{Statistical analysis methods}

To answer the research questions and verify the validity of its hypotheses, the following statistical methods were used: The simple correlation coefficient, which was used to measure the strength of the relationship between the explanatory variable and the responsive variable. Simple and multiple linear regression, where it was used to choose the effect of the explanatory variable on the response variable.

\subsection{The limits of the study}

These are the locations of companies that have spread throughout the city of Kirkuk. It extends from $12 / 10 / 2019$ to $25 / 1 / 2020$. According to the variables of the study, the groups that have an important and interacting effectively with the variables of the study have been approved, and they are (Chairman of the Board, Board Members, General Manager and his assistants, department managers).

\subsection{The researched companies and the individuals surveyed}

The goals that the study sought to achieve were referred to as the main determinant in selecting the sample. The study sample consisted of four companies operating in the private industrial sector in Kirkuk Governorate. The reason for choosing these organizations as a sample for the study is due to the suitability of these companies to diagnose the features of the purpose structure and strategic performance more than other sectors. The following is a brief explanation of these companies:

- Northern Region Company: This company was established in 1964 as a private company and then it was nationalized in 1972 by the state and worked from 1972 until 1989 as a public company, then in 1989 it was transformed into a private joint-stock company and this company markets its products inside Iraq. And produces several types of soft drinks, especially Pepsi-Cola.

- Al-Tamim Company: The Nationalization Company for Soft Drinks is one of the newest companies in the governorate. It was established in 2002 and its board of directors consists of five members. It is one of the important companies in the field of soft drinks production, as it produces several types of these drinks and markets its production inside Iraq.

-Beirut company: This company was established in 1989 and has been operating since 1981 as a factory for the production of agricultural equipment. Its board of directors has five members who are shareholders of this company. This company has evolved through its path to open new production lines and market its products in the local market in addition to equipping the Ministry of Agriculture with agricultural equipment.

- Kirkuk Company: This company was established in 1971 and this company produces several types of ice cream and markets its products in the Iraqi local market.

\section{The Practical Side}

This side explains the test of study hypotheses, as follows:

4.1. Test of first hypothesis: (There is a positive correlation between the organization's adhocracy structure with its strategic performance in the researched organizations). To answer the first question in the study and test the relationship hypothesis, a Pearson correlation coefficient was used to find out the correlation between the organization's adhocracy structure and its strategic performance, and the results were as in Table 1.

Table 1. Correlation coefficients between the adhocracy structure and strategic performance.

\begin{tabular}{ccccc}
\hline Variable & test & $\begin{array}{c}\text { Adhocracy Structure } \\
\text { (overall index) }\end{array}$ & $\begin{array}{c}\text { Administrative } \\
\text { Adhocracy }\end{array}$ & $\begin{array}{c}\text { Operating } \\
\text { Adhocracy }\end{array}$ \\
\hline Strategic Performance & $(\mathrm{R})$ & $0.754^{* *}$ & $0.698^{* *}$ & $\mathbf{0 . 6 3 2} * *$ \\
& $\mathrm{Sig}$ & 0.000 & 0.000 & $\mathbf{0 . 0 0 0}$ \\
\hline
\end{tabular}


(**) Correlation is significant at $(0.01)$ level.

It can be shown from Table 1. that there is a positive and significant correlation relationship between the adhocracy structure and strategic performance at the macro level, as the correlation coefficient reached (0.754) and this result supports the validity of the correlation relationship hypothesis, and it was found that the direction of the correlation between the two variables, and also note the correlations between the dimensions of the adhocracy structure and strategic performance where we note the value of the correlation coefficient between the administrative adhocracy and the strategic performance of (0.698), as well as the value of the correlation coefficient between the operating adhocracy and the strategic performance of (0.632). This confirms the acceptance of the first hypothesis

4.2. Test of second hypothesis: (There is a significant effect of the organization's adhocracy structure of the strategic performance in the researched organizations). To answer the second question in the study and test the hypothesis of impact, multiple linear regression analysis was used to verify the impact of the adhocracy structure of the strategic performance, and the results were as in Table 2.

Table 2.The results of the impact of the Adhocracy Structure of the Strategic Performance.

\begin{tabular}{|c|c|c|c|c|c|c|c|c|c|}
\hline Sig* & $\mathrm{T}$ & $\beta e t a$ & B & $\begin{array}{c}\text { Dimension of } \\
\text { Adhocracy } \\
\text { Structure }\end{array}$ & Sig* & $\mathrm{F}$ & $\begin{array}{l}\text { Adjusted } \\
\mathrm{R}^{2}\end{array}$ & $\mathrm{R}^{2}$ & $\mathbf{R}$ \\
\hline $0.00 *$ & 4.252 & 0.467 & 0.489 & $\begin{array}{l}\text { Operating } \\
\text { Adhocracy }\end{array}$ & & & & & \\
\hline $0.00 *$ & 5.453 & 0.532 & 0.619 & $\begin{array}{c}\text { Administrative } \\
\text { Adhocracy }\end{array}$ & 0.000 & 39.278 & 0.591 & 0.64 & 0.754 \\
\hline
\end{tabular}

(*) The effect is statistically significant at $(\alpha \leq 0.05)$.

Table 2 shows, that there is an effect of the adhocracy structure of the strategic performance in the researched organizations, which confirms the significance of this effect, the value of $(\mathrm{F})$, which amounted to (39.278), which is a significant function at the level of significance (0.00), while the determination factor (R2) was (0.64), meaning that its value (64\%) of the changes in strategic performance in the organizations resulted from the change in the adhocracy structure, and in the same context, the results of the analysis showed that the (adjusted R2) has reached (0.591), which reflects the level of interest in the adhocracy structure after eliminating the values of standard errors resulting from the strategic performance, and what remains $(36 \%)$ due to other factors that are not visible. In the study form. And to verify the effect of each dimension of the adhocracy structure of the strategic performance. It is noted from Table 2. that there is a significant effect of the operating adhocracy on the strategic performance, as the value of the parameter ( $\beta$ eta) reached $(0.467)$ at the level of statistical significance $(0.00)$ which is less than the level of moral significance (0.05), and what confirms this significance value (T) Selfadministered control amounting to $(4,252)$. It is also noted from Table 2. that there is a significant effect for the administrative adhocracy of the strategic performance, as the value of the parameter ( $\beta$ eta) reached (0.532) at the level of statistical significance (0.00) which is smaller than the level of moral significance (0.05), and what confirms this significance value (T) Systematic thinking of systems whose value is $(5,453)$. This confirms the acceptance of the second hypothesis.

4.3. Test of third hypothesis: (The organization's adhocracy structure contributes of the strategic performance of the researched organizations). To answer the third question from the study questions and testing the contribution hypothesis, use the (Paired sample T-Test) option to identify the contribution of the dimensions of the adhocracy structure of the strategic performance, and the arrangement of the dimensions according to the degree of contribution from the highest to the lowest, and as in Table 3.

Table 3. Choosing (Paired sample T-Test)

\begin{tabular}{lccc}
\hline Variables & $\begin{array}{c}\text { Sig. } \\
\text { (2-tailed) }\end{array}$ & T & Result \\
\hline
\end{tabular}




\begin{tabular}{cccl} 
Administrative & & & \\
Adhocracy & $0.00 *$ & 5.453 & Statistically significant \\
Operating Adhocracy & $0.00 *$ & 4.252 & Statistically significant \\
Adhocracy Structure & $0.00 *$ & 5.673 & Statistically significant \\
\hline
\end{tabular}

(*) Significant at $(\alpha \leq 0.05)$.

We notice in Table 3. that all dimensions of the adhocracy structure are statistically significant at a level of significance less than the level of significance $(0.05 \geq \alpha)$, and this indicates the validity of the third hypothesis, and came first (administrative adhocracy) in terms of the highest degree of contribution, while came second (operating adhocracy) at the least degree of contribution to the strategic performance, and these results indicate that the strategic performance of the organizations can be strengthened by the research organizations seeking to apply the adhocracy structure by focusing on the administrative adhocracy as well as adopting the operating adhocracy. Likewise, the normal distribution of the variables of the study has been adopted, where a choice (Shapiro - Wilk Test) was made, to verify that the study data is free of statistical problems that may negatively affect the results of the study, and as shown in Table 4.

Table 4. The normal distribution of the study variables

\begin{tabular}{cccc}
\hline Paragraph sequence & Dimensions & Shapiro-Wilk & Sig.* (Statistical significance) \\
\hline $\mathbf{1}$ & Administrative Adhocracy & 0.971 & $\mathbf{0 . 2 5 1}$ \\
$\mathbf{2}$ & Operating Adhocracy & 0.952 & $\mathbf{0 . 0 8 1}$ \\
$\mathbf{3}$ & Financial approach & 0.976 & $\mathbf{0 . 1 5 2}$ \\
$\mathbf{4}$ & Cognitive approach & 0.902 & $\mathbf{0 . 0 9 1}$ \\
$\mathbf{5}$ & Stakeholder approach & 0.932 & $\mathbf{0 . 1 1 4}$ \\
$\mathbf{6}$ & Competitive Values approach & 0.957 & $\mathbf{0 . 1 7 1}$ \\
\hline
\end{tabular}

(*) The distribution is normal when it is greater than the significance level (0.05).

\section{Conclusions and Recommendations}

The study presented a systematic attempt to diagnose and analyze a set of variables. Based on the results reached, we present the most important conclusions and recommendations as follows:

1. The results of the field study analysis showed a positive correlation between the adhocracy structure and strategic performance in the researched organizations.

2. The results of the field study analysis revealed that there is a significant effect of the adhocracy structure on the strategic performance in the researched organizations, where the impact factor reached $64 \%$. This makes the adhocracy structure an appropriate independent dimension to improve strategic performance in the research organizations.

3. The results of the analysis revealed a contribution to the adhocracy structure model in the strategic performance of the researched organizations. Where we note that all dimensions of the adhocracy structure model are statistically significant, and came first after (administrative adhocracy) in terms of the highest degree of contribution, while after (operating adhocracy) obtained the lowest degree of contribution to improving strategic performance, and these results indicate that the strategic performance of the organizations It can be strengthened by seeking researched organizations to apply the adhocracy structure model, through the administrative adhocracy and the operating adhocracy.

Based on the conclusions, we present some recommendations to the organizations as follows:

1. Adoption of the dimensions of the adhocracy structure, which are built on objective grounds according to the needs of the organizations for the administrative adhocracy and the operating adhocracy and the selection of the best mix for the dimensions of the study in a manner that is compatible with its activities to enhance strategic performance, and follow-up, evaluation and development of workers' knowledge to reach a flexible organization capable of enhancing its strategic performance.

2. The need to attract research organizations to cadres with different cognitive disciplines and able to work according to flexible structures because of their significant role in enhancing strategic performance. 3. The field reality dictates that the research organizations and other Iraqi organizations enhance their strategic performance to deal with the changes that were expected for the adhocracy structure model. 


\section{References}

[1]Schmidt, Thomas.: A Review of Structure in Fives; Designing Effective Organizations, American Journal of Management Care, Vol.8, No. 2. pp. 13. (2006)

[2]Robbins, Stephen P., \& Judge, Timothy A.: Organization Behavior, 13th.ed., Prentice-Hall, Inc., Upper Saddle River, New Jersey. pp. 531-532 (2009)

[3]Robbins, Stephen P.: Organization Theory: Structure, Design and Applications, Prentice-Hall, Englewood Cliffs, New York. pp. 175-176. (1990)

[4]Mintzberg, Henry.: The Structuring of Organization, Prentice-Hall, Englewood Cliffs, N. J., USA. pp. 4. ( 1979)

[5]Hatch, Mary Jo.: Organization Theory: Modern, Symbolic, and Postmodern Perspectives, Oxford University Press, Great Britain. pp. 170. (1997)

[6]Gabson, James I., et. al.: Organization: Behavior, Structure, Processes, McGraw-Hill Irwin, U.S.A. pp. 394. (2003)

[7]Al-Salem, Muayad Saeed.: Organization Theory, Structure and Design, Wael House for Publishing and Distribution, Amman, Jordan. I 1. pp. 183-189. (2000)

[8]Al-Shalabi, Firas Suleiman Hassan.: The Impact of Merger on Financial Performance, Master Thesis, College of Administration and Economics, University of Mosul. pp. 54. (2002)

[9]Sultan, Hikmat Rashid, \& Al-Tawil, Akram.: The effect of cost and quality in enhancing strategic performance, Al-Rafidain Development Magazine, volume 24, No. 67. pp. 58. (2002)

[10]Obaid, Abdul-Salam Ibrahim.: the philosophy of comprehensive quality management and its impact on strategic performance, $\mathrm{PhD}$ thesis, College of Administration and Economics, University of Baghdad. pp. 104. ( 2003)

[11]Cokins, Gary.: Strategic performance Management, www. Pceo. us. pp. 2. (2003)

[12]Atkinson, Anthony, A.: Strategic performance Measurement and Incentive Compensation, www.arts.uwater ca. pp. 3. ( 1998)

[13]Al-Hussaini, Falah Hasan.: Strategic Management - Its Concepts - Its Entrances - Its Contemporary Operations, First Edition, Wael House for Printing and Publishing, Amman, Jordan. pp. 239. (2000)

[14]Mustafa, Shuaib Ibrahim.: The effect of cultural knowledge and creative behavior on the level of performance of some industrial organizations, $\mathrm{PhD}$ thesis, College of Administration and Economics, University of Mosul. pp. 39. ( 1998)

[15]Rughase, olaf.: Strategic performance Measurement, Agongnitine approach. www. Hcp. enst, Ed, Dubledy, New York. pp. 395 (1999)

[16]Atkinson , Anthony \& et. Al.: stakeholder approach to strategic Performance , Measurement , www.mit.edu.smr.issue. pp. 2 (2004) 